\title{
Bayer MaterialScience eröffnet in Dubai neues Labor
}

Bayer MaterialScience hat in Dubai ein Labor für Lacke, Klebstoffe und Spezialitäten in Betrieb genommen. Das Entwicklungs- und Anwendungslabor bietet kundenspezifische technische Unterstützung im Nahen Osten und Afrika. Es ist im Hause des DuBiotech untergebracht, des führenden Clusters für Biowissenschaften in der Region.

$\mathrm{N}^{\mathrm{s}}$ eben Anwendungen in den Kernbereichen Bau-, Automobil-, Industrie-, Kunststoff-, Holz- und Möbellacke wird das Labor auch die Entwicklung von Polyurethan-Produkten für verschiedene Hochleistungsanwendungen vorantreiben. Aktuelle Beispiele sind Dichtstoffe für Betonierfugen und Flughafen-Rollbahnen sowie lösemittelfreie Beschichtungen für Rohrleitungen. Außerdem soll das Labor maßgeschneiderte Lösungen für Hersteller von Kleb- und Dichtstoffen in den Bereichen Transport, Bau, Möbel, Verpackung und Schuhe entwickeln.

Dazu Daniel Meyer, Leiter des Bereichs Lacke, Klebstoffe, Spezialitäten und Mitglied der erweiterten Geschäftsleitung von Bayer MaterialScience: „Wir müssen unsere Ressourcen auf die Marktanforderungen ausrichten. Deshalb investieren wir gezielt in einzelnen Regionen, um unsere führende Marktposition

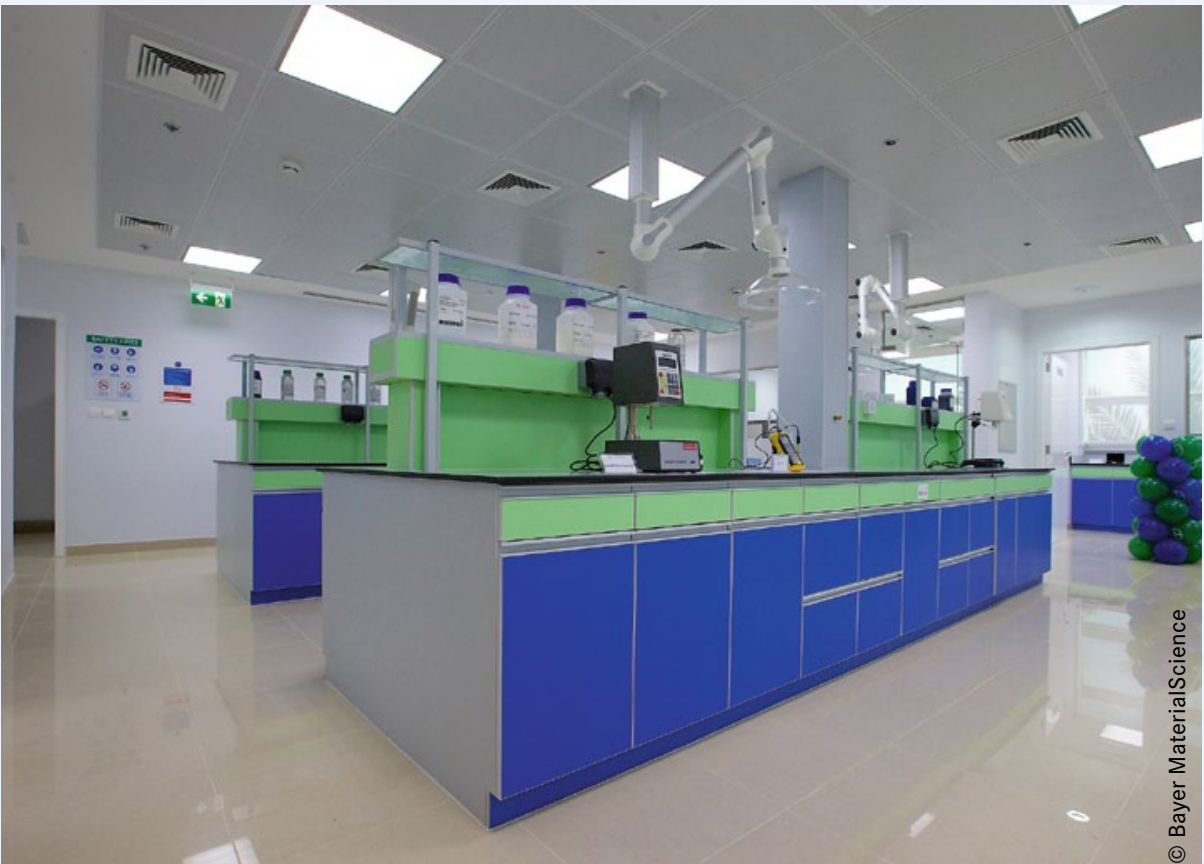

Blick ins Innere des neuen Labors zu erhalten oder weiter auszubauen.“ Das Labor wird eng mit dem globalen Bayer-Kompetenz-Netz für Beschichtungen zusammenarbeiten. Dies betrifft vor allem die bestehenden Labore und Technikums-Einrichtungen in Indien, China, Japan, Russland, Brasilien, den USA, Spanien und Deutschland. Die neue Einrichtung ist im DuBiotech in Dubai untergebracht und mit modernsten Prüf- und Anwendungsgeräten ausgestattet. Ebenso wie das Wissenschaftszentrum arbeitet auch das Bayer-Labor im Einklang mit weltweiten Normen und Richtlinien.

\section{Bossard beteiligt sich an BigHead}

Die Bossard Gruppe beteiligt sich am britischen Unternehmen BigHead, bekannt auf dem Gebiet anspruchsvoller Verbindungslösungen. Besonderer Vorteil dieser Beteiligung ist die globale Vertriebspartnerschaft außerhalb von Großbritannien.

$\mathrm{B}$ igHead hat sich insbesondere im Leichtbau und speziell im Verbundwerkstoffbereich einen Namen gemacht. So zählen Automobil-Premiumhersteller wie Rolls Royce Motors, BMW, Aston Martin und Lamborghini ebenso zu den Abnehmern wie die renommierten Schiffsbauer Sunseeker Yachts und RNLI. Die Kunden von BigHead finden sich außerdem in der Bauwirtschaft, Petrochemie und Windenergie. Die Produktpalette von BigHead umfasst gegenwärtig 400 Standardausführungen, doch lassen sich die unter dem Markennamen BigHeads bekannten Befestigungselemente auch kundenspezifischen Vorstellungen anpassen. BigHead erwirtschaftete 2013 einen Umsatz von rund 4,0 Mio. CHF. Bossard sieht im Geschäft des britischen Unternehmens ein großes Wachstumspotenzial, zumal es künftig vom weltweiten Vertriebsnetz der Bossard Gruppe profitieren wird.

Die Bossard Gruppe erzielte 2013 mit gut 1800 Mitarbeitenden an über 60 Standorten weltweit einen Umsatz von 609,7 Mio. CHF. 